\title{
A Within-Subjects, Within-Task Demonstration of Intact Spatial Reference Memory and Impaired Spatial Working Memory in Glutamate Receptor-A-Deficient Mice
}

\author{
Wolfram B. Schmitt, ${ }^{1}$ Robert M. J. Deacon, ${ }^{1}$ Peter H. Seeburg, ${ }^{2}$ J. Nicholas P. Rawlins, ${ }^{1}$ and David M. Bannerman ${ }^{1}$ \\ ${ }^{1}$ Department of Experimental Psychology, University of Oxford, Oxford OX1 3UD, United Kingdom, and ${ }^{2}$ Department of Molecular Neurobiology, Max- \\ Planck Institute of Medical Research, D-69120 Heidelberg, Germany
}

Gene-targeted mice lacking the AMPA receptor subunit glutamate receptor-A (GluRA) (GluR1) and wild-type controls were compared on a radial-maze task in which the same three of six arms were always baited, but in which the rewards of milk were not replaced within a trial. This procedure allowed not only a within-subjects but also a within-trials assessment of both spatial working memory (WM) and reference memory (RM) in GluRA ${ }^{-1-}$ mice, using identical spatial cues. In experiment 1 , the GluRA ${ }^{-1-}$ mice made more WM and RM errors during task acquisition. However, separate groups of $\mathrm{GluRA}^{-1-}$ and wild-type mice (experiment 2) acquired a purely RM version of the task at a similar rate, using a paradigm with which it was not possible to make WM errors (doors prevented mice from re-entering an arm that they had already visited on that trial). In contrast, mice with hippocampal lesions were dramatically impaired. These results are consistent with the possibility that the WM impairment in the GluRA ${ }^{-1-}$ mice during experiment 1 produced interference that disrupted RM acquisition. A WM component was therefore introduced after RM acquisition in experiment 2 (i.e., the mice were no longer prevented from re-entering a previously visited arm). The $\mathrm{GluRA}^{-1-}$ mice now made considerably more WM errors than did wild-type mice, but simultaneously, RM was only mildly and transiently impaired. These experiments provide additional evidence of a selective spatial WM deficit coexisting with intact spatial RM acquisition in $\mathrm{GluRA}^{-1-}$ mice, suggesting that different neuronal mechanisms within the hippocampus may support these different kinds of information processing.

Key words: AMPA receptors; LTP; hippocampus; spatial memory; radial maze; mice

\section{Introduction}

It has been widely suggested that physiological processes resembling long-term potentiation (LTP) in the hippocampus may underlie spatial learning in the mammalian brain (Bliss and Lømo, 1973; Martin et al., 2000). However, the relationship between hippocampal (HPC) LTP and spatial learning may be less straightforward than previously imagined. For example, Zamanillo et al. (1999) showed that gene-targeted mice lacking the AMPA receptor subunit glutamate receptor-A (GluRA) (GluR1) demonstrated normal acquisition of a spatial reference memory (RM) water maze task, despite an absence of hippocampal LTP at CA3 $\rightarrow$ CA1 synapses. More recently, Reisel et al. (2002) have shown that, although water maze acquisition is normal in these GluRA $^{-1-}$ mice, they are dramatically impaired during discretetrial, rewarded alternation on the elevated T-maze, another hippocampus-dependent memory task. This has led us to suggest that GluRA-dependent forms of synaptic plasticity may be required for spatial working memory (WM) (e.g., T-maze), but that GluRA-independent mechanisms in the hippocampus may be sufficient to support spatial RM (e.g., water maze).

The concept of distinct WM and RM systems was first pro-

\footnotetext{
Received 0ct. 17, 2002; revised Feb. 19, 2003; accepted Feb. 24, 2003.

This work was supported by European Union Framework V Grant QLG3-CT-1999-01022. We thank Greg Daubney and Dr. Jonathan Flint for their assistance with genotyping.

Correspondence should be addressed to Dr. David M. Bannerman, Department of Experimental Psychology, University of 0xford, South Parks Road, 0xford, 0X1 3UD, UK. E-mail: david.bannerman@psy.ox.ac.uk. Copyright @ 2003 Society for Neuroscience $\quad$ 0270-6474/03/233953-06\$15.00/0
}

posed by Honig (1978) and developed by Olton and colleagues and was derived primarily from studies using the radial-arm maze (Olton and Samuelson, 1976; Olton et al., 1979). The radial maze consists of a number of arms (commonly 6,8 , or 12) radiating out from a central area like spokes from a wheel. The aim of the task for the animal is to collect hidden rewards of food located at the ends of the arms, by using the distal extramaze cues around the laboratory. Because the food rewards are not replaced, the animal has to adopt a win-shift strategy and remember which arms it has already visited. This provides a test of spatial WM. By baiting only certain arms but always baiting the same arms, spatial RM can also be assessed at the same time. Radial-maze performance is disrupted by hippocampal lesions in rats (Olton et al., 1979; Jarrard, 1983).

The aim of the present study was to simultaneously assess spatial WM and RM in GluRA ${ }^{-1-}$ mice, using a radial-arm maze task in which the same three of six arms are always baited, but in which the food rewards are not replaced within a trial. Whereas previously we demonstrated a clear dissociation between spatial WM and RM using different behavioral tests conducted separately at different times and in different spatial environments with different spatial cues (Reisel et al., 2002), the present experiments allow WM and RM components of spatial learning to be dissociated not only within subjects but also within the same trial. Importantly, the WM and RM components of the task are assessed using identical spatial cues. Furthermore, the sensorimotor and motivational demands of the two components of the task are also the same. 


\section{Materials and Methods}

Subjects. Experiments 1 and 2 were conducted with experimentally naive, age-matched, female wild-type and GluRA ${ }^{-1-}$ mice, which were bred in the Department of Experimental Psychology at the University of Oxford [for details of genetic construction, breeding, and subsequent genotyping, see Zamanillo et al. (1999)]. Experiment 3 consisted of two groups of C57BL/6J mice obtained from Harlan Olac (Oxon, UK) that had received either bilateral NMDA-induced cytotoxic hippocampal lesions or sham surgery [for details of methodology, see Deacon et al. (2002)]. Mice were housed in group cages and tested during the light phase of the day (7:00 A.M. to 7:00 P.M.). Mice had ad libitum access to water but were maintained on a restricted feeding schedule at $85 \%$ of their free-feeding weight throughout the behavioral testing. All experiments were conducted under the auspices of the United Kingdom Home Office Project and personal licenses held by the authors.

Apparatus. Spatial memory was assessed using a six arm radial maze that was made of wood and painted gray. Each arm $(60 \times 7 \mathrm{~cm})$ was surrounded by a $1 \mathrm{~cm}$ raised edge and extended from a circular central platform (18 cm diameter). At the end of each arm was a stainless-steel food well. Mice were rewarded with $0.1 \mathrm{ml}$ of sweetened, condensed milk (diluted 50:50 with water). The maze was elevated $80 \mathrm{~cm}$ above the floor in a well lit laboratory $(6.3 \times 2.7 \mathrm{~m})$ that contained various extramaze cues (e.g., laboratory equipment, stools, bench, and posters). In experiments 2 and 3, the central platform was surrounded by a transparent Perspex cylinder (18 cm diameter; $30 \mathrm{~cm}$ high). At the entrance to each arm of the maze was a Perspex door ( $6 \mathrm{~cm}$ wide; $7 \mathrm{~cm}$ high) that could be controlled by the experimenter using a series of strings.

Experiment 1. In the first experiment, 12 wild-type and $11 \mathrm{GluRA}^{-1-}$ mice were used. The mice were first habituated to drinking sweetened, condensed milk on two arms of an elevated Y-maze (Reisel et al., 2002) in their colony holding room (i.e., not the testing room). Once all the mice were running freely on the Y-maze and readily consuming the milk rewards, testing on the radial-arm maze began.

Mice were trained on a radial-maze task in which the same three of six arms were always baited but in which the milk rewards were not replaced within a trial. The three baited arms were allocated such that two of these arms were adjacent, and the third was between two nonrewarded arms (e.g., arms 1, 2, and 4). Different combinations of arms were used as much as possible, although the arm allocations were counterbalanced across groups. At the start of a trial, a mouse was placed individually on the central platform. Mice were allowed to explore freely and consume all of the milk rewards available. There were no doors present in this experiment. Three types of error were scored (Jarrard, 1983, 1993): RM errors were defined as entries into arms that were never baited, working memory-correct (WM-C) errors were scored when a mouse entered an arm that was correct but that had already been visited on that trial, and working memory-incorrect (WM-I) errors occurred when an animal made repeated entries into an arm that was never baited. Mice received 24 trials in total. The maze was rotated periodically to prevent the mice from using intramaze cues to solve the task.

Each type of memory error (RM, WM-C, and WM-I) was analyzed separately. The data were analyzed in blocks of four trials. Where the assumptions of normality and equal variance were met, data were analyzed by ANOVA with subsequent analysis of simple main effects where appropriate. If the data failed to satisfy these assumptions, transformations were applied, and ANOVA was performed on the transformed data set. In cases in which transformation failed to improve the distribution of the data, additional nonparametric Kruskal-Wallis ANOVAs on ranks were performed as an additional test for group differences. To make the figures more legible, however, all of the data are presented as untransformed means \pm SEM.

Experiment 2. New groups of experimentally naive wild-type $(n=11)$ and GluRA ${ }^{-1-}(n=10)$ mice were used for this experiment. After habituation (see experiment 1), the mice were tested on a three-from-six radial-maze task similar to that used in experiment 1 , except that on this occasion, Perspex doors prevented mice from re-entering an arm that they had already visited on that trial. All of the doors were closed each time the mice returned to the central platform, and confined the mice there until the next choice was made. Once an arm had been visited, its door remained closed for subsequent choices. Thus, all six doors were open for the first choice, five for the second choice, four for the third choice, and so on. Using this testing procedure, it was not possible for the mice to make WM errors (WM-C or WM-I). As in experiment 1, RM errors (maximum of three) were scored when mice entered an arm that was never baited. All other aspects of testing were identical to those of experiment 1 .

Retention of the spatial RM task was then determined. After a $10 \mathrm{~d}$ interval, performance was reassessed during an additional 12 trials using the same testing procedure. This continued testing also served to ensure that all of the mice were performing at a very high level on the RM version of the task before introducing the WM component.

The WM component of the task was then introduced. The mice received an additional eight trials in which the same three of six arms were baited, but now they were no longer prevented from re-entering a previously chosen arm. The doors were used solely to retain the animals on the central platform between choices. RM, WM-C, and WM-I errors were scored for these trials as in experiment 1 .

Experiment 3. Radial-maze performance was also assessed in sham $(n=11)$ and HPC-lesioned $(n=10)$ C57BL/6J mice. As in the first part of experiment 2, the same three of six arms were always baited, and the Perspex doors prevented the mice from re-entering an arm that they had already visited on that trial. The number of RM errors was scored as before. Mice received 24 trials in total. All other aspects of the testing procedure were identical to the first phase of experiment 2.

\section{Results}

\section{Experiment 1}

Wild-type mice successfully acquired the three-from-six radialmaze task. They made progressively fewer RM errors as training proceeded and made very few WM errors (WM-C or WM-I) at any stage of testing (Fig. 1). In contrast, and somewhat surprisingly in view of our hypothesis (Reisel et al., 2002), the GluRA ${ }^{-1-}$ mice were dramatically impaired, not only in terms of WM performance but also in terms of RM choice accuracy, making more of all three error types (RM, WM-C, and WM-I). An ANOVA of RM errors revealed a significant main effect of group $\left(F_{(1,21)}=\right.$ 19.2; $p<0.0005)$, a significant main effect of block $\left(F_{(5,105)}=\right.$ $13.2 ; p<0.00001)$, and a group-by-block interaction $\left(F_{(5,105)}=\right.$ $3.9 ; p<0.005$ ) (Fig. $1 A$ ). In terms of WM-C errors, there were significant main effects of group $\left(F_{(1,21)}=58.6 ; p<0.00001\right)$ and block $\left(F_{(5,105)}=3.6 ; p<0.005\right)$ but no significant group-byblock interaction $\left(F_{(5,105)}=1.8 ; p>0.10\right)$ (Fig. $\left.1 B\right)$. Analysis of WM-I errors revealed significant main effects of group $\left(F_{(1,21)}=\right.$ $65.3 ; p<0.00001)$ and block $\left(F_{(5,105)}=12.2 ; p<0.00001\right)$ and a group-by-block interaction $\left(F_{(5,105)}=5.7 ; p<0.0005\right)$ (Fig. $\left.1 C\right)$. Although there were dramatic impairments in the GluRA ${ }^{-1-}$ mice in terms of both WM-C and WM-I errors, strictly speaking, the data sets for both of these measures failed to satisfy the assumptions required for ANOVA. Transforming the data failed to improve the distributions. Consequently, we conducted separate Kruskal-Wallis $(\mathrm{H})$ tests to compare the total number of WM-C and WM-I errors made by wild-type and GluRA ${ }^{-/-}$mice across all six blocks of testing. These tests confirmed the results obtained from the parametric ANOVAs. The GluRA ${ }^{-1-}$ mice made significantly more of both kinds of WM errors (WM-C - H $(1)=16.6$; $p<0.0001$; WM-I $-\mathrm{H}(1)=16.5 ; p<0.0001)$. Close inspection of the data revealed that two wild-type and three GluRA ${ }^{-1-}$ mice showed evidence of a circling strategy during which they repeatedly turned in the same direction and entered the adjacent arm on each choice within a trial. For one wild-type mouse and two GluRA $^{-1-}$ mice, this became a persistent strategy. However, this was clearly not the basis for the deficit in the GluRA ${ }^{-1-}$ group as a whole. 

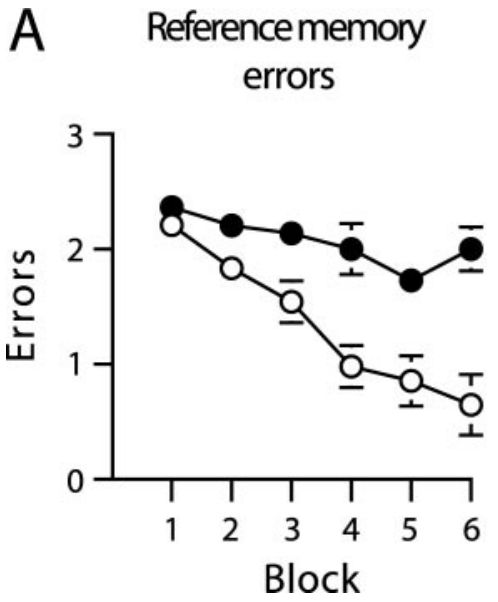

B
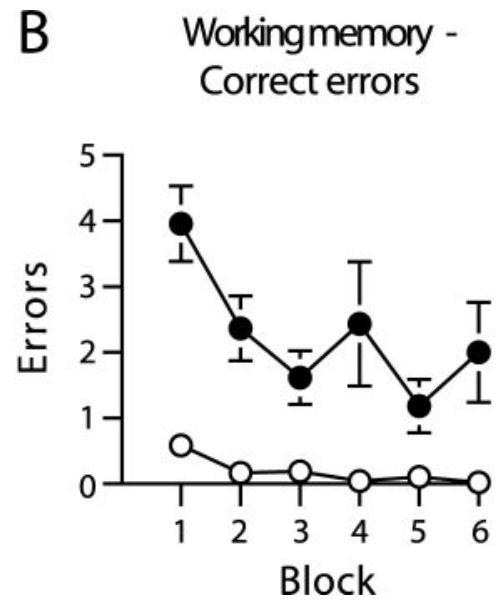
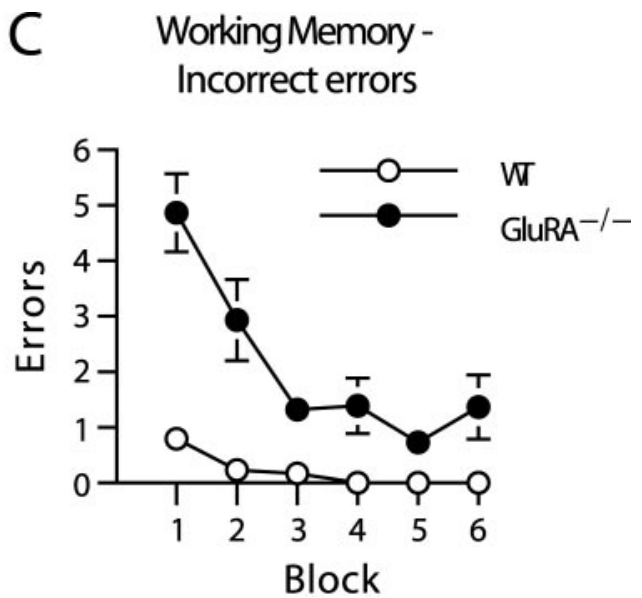

Figure 1. GluRA ${ }^{-1-}$ mice make more spatial reference and working memory errors during acquisition of a radial-maze task in which the same three of six arms were always baited but in which the food rewards were not replaced within a trial. The mean \pm SEM number of RM errors ( $A$ ), WM-C errors ( $B$ ), and WM-I errors ( $C$ for wild-type (WT; white circles) and GluRA ${ }^{-1-}$ (black circles) mice during six blocks of training ( 4 trials per block) is shown. Where error bars appear absent, the error is too small to be visible.

The deficit in spatial RM displayed by the GluRA ${ }^{-1-}$ mice in this experiment is at odds with previous studies that have shown normal RM acquisition in these mice using a variety of different behavioral tests (Zamanillo et al., 1999; Reisel et al., 2002). One possible explanation is that, by using this particular testing procedure, impaired WM performance in GluRA ${ }^{-1-}$ mice may produce interference that subsequently disrupts RM performance. For example, if a GluRA ${ }^{-1-}$ mouse makes a WM-C error on this version of the task and re-enters a normally correct but previously visited arm, then it will receive no milk in an arm that is usually rewarded. This might result in a reduction in the reward valence of that particular arm and in impaired spatial RM performance. If this hypothesis is correct, then spatial RM performance should proceed normally in GluRA ${ }^{-1-}$ mice under conditions in which it is not possible to make WM errors. Experiment 2 addressed this possibility.

\section{Experiment 2}

In contrast to the results of experiment 1, both wild-type and GluRA $^{-1-}$ mice successfully acquired the three-from-six radialmaze task under conditions in which it was not possible to make WM errors (Fig. 2). There was no evidence of any spatial RM impairment in the GluRA ${ }^{-1-}$ mice. An ANOVA of RM errors revealed that there was no significant main effect of group $\left(F_{(1,19)}=2.5 ; p>0.10\right)$. There was, however, a significant main effect of block $\left(F_{(5,95)}=77.8 ; p<0.0001\right)$ and a group-by-block interaction $\left(F_{(5,95)}=3.6 ; p<0.01\right)$. Subsequent analysis of simple main effects revealed that this was attributable to the fact that the GluRA ${ }^{-1-}$ mice were actually performing significantly better than the wild-type mice on block 4 of testing $\left(F_{(1,92)}=7.7 ; p<\right.$ 0.01 ).

Retention of spatial RM was unaffected in the GluRA ${ }^{-1-}$ mice (Fig. 2). Although both groups showed some evidence of forgetting (i.e., a small increase in the number of RM errors), there were no differences between the two groups. First, an ANOVA comparing wild-type and GluRA ${ }^{-1-}$ mice across the last block of acquisition (block 6) and the first block of retention testing revealed a significant main effect of block, suggesting that forgetting had occurred $\left(F_{(1,19)}=40.5 ; p<0.0001\right)$. There was, however, no main effect of group $\left(F_{(1,19)}=2.7 ; p>0.10\right)$ and no group-by-block interaction $\left(F_{(1,19)}=1.1 ; p>0.20\right)$. A second ANOVA of RM errors made during all three blocks of retention

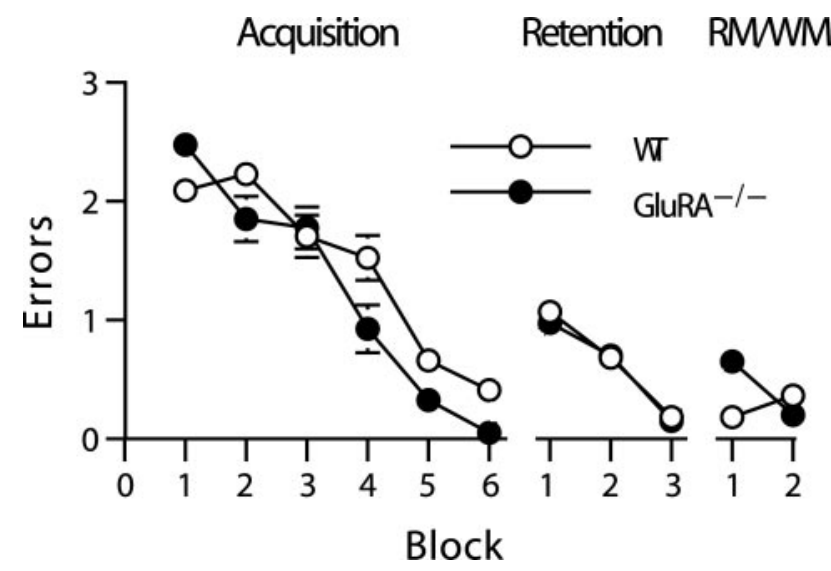

Figure 2. GluRA ${ }^{-1-}$ mice show normal spatial reference memory performance on a threefrom-six radial-maze task in which doors prevent mice from making working memory errors during the acquisition phase. The mean \pm SEM number of RM errors is shown for wild-type (WT; white circles) and GluRA ${ }^{-1-}$ (black circles) mice during six blocks of training in which doors prevented mice from making working memory errors (Acquisition; 4 trials per block) (left), three blocks of spatial reference memory retention testing after a $10 \mathrm{~d}$ interval with doors still preventing WM errors (Retention; 4 trials per block) (center), and a final two blocks of testing during which the doors were then no longer used to prevent working memory errors (RM/WM; 4 trials per block) (right). Where error bars appear absent, the error is too small to be visible.

testing revealed neither a main effect of group nor a group-byblock interaction $(F<1 ; p>0.20$ for both comparisons). There was, however, a significant main effect of block $\left(F_{(2,38)}=34.2\right.$; $p<0.00001$ ), which reflected the fact that both groups of mice rapidly relearned the task.

When the doors were then no longer used to prevent re-entry into a previously visited arm, the GluRA ${ }^{-1-}$ mice showed only a mild, transient spatial RM impairment (Fig. 2). Although the GluRA $^{-1-}$ mice made more RM errors on the first two trials of block 1 of this phase of the experiment, they were soon performing as well as the controls on this measure and, by the end of testing, were actually performing better than their wild-type counterparts. These impressions were confirmed by an ANOVA of RM errors for these two blocks of testing. There was no significant main effect of group $\left(F_{(1,19)}=2.4 ; p>0.10\right)$ and a nonsignificant effect of block $\left(F_{(1,19)}=2.6 ; p>0.10\right)$. There was, however, a significant group-by-block interaction $\left(F_{(1,19)}=14.5 ; p<\right.$ 


\section{Working memory-Correct errors}

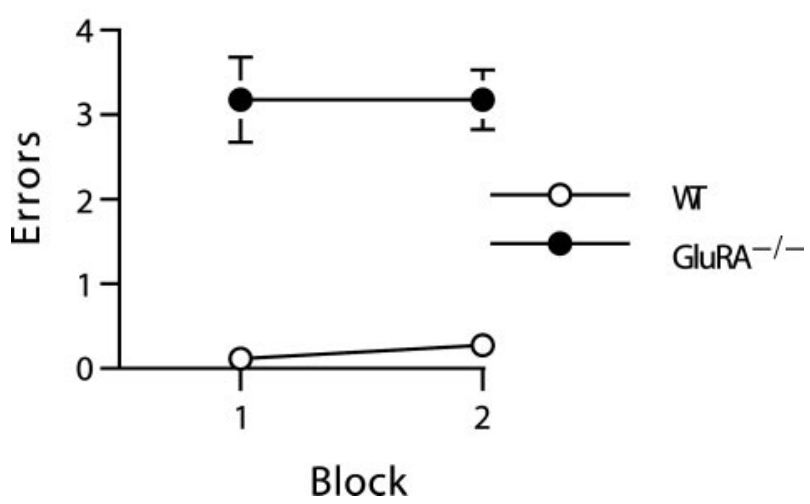

Figure 3. GluRA ${ }^{-1-}$ mice display a robust spatial working memory impairment in the absence of a lasting spatial reference memory impairment on the three-from-six radial-maze task in which the doors were now no longer used to prevent working memory errors (see also Fig. 2, right). The mean \pm SEM number of WM-C errors for wild-type (WT; white circles) and GluRA $^{-1-}$ mice (black circles) is shown during two blocks of testing (RM/WM; 4 trials per block). Where error bars appear absent, the error is too small to be visible.

0.005). Subsequent analysis of simple main effects confirmed that the GluRA ${ }^{-1-}$ mice made significantly more RM errors during block $1\left(F_{(1,37)}=13.2 ; p<0.001\right)$, and that there were no group differences during block $2\left(F_{(1,37)}=1.6 ; p>0.20\right)$. During block 2 , both groups of mice showed a high level of performance, making very few RM errors.

At the same time, the GluRA ${ }^{-1-}$ mice did, however, make considerably more WM-C errors than did their wild-type counterparts throughout this phase of the experiment (Fig. 3). Because the data failed to conform to the assumption of equal variance, they were subjected to a square root transform before ANOVA. This ANOVA revealed a significant main effect of group $\left(F_{(1,19)}=\right.$ 157.6; $p<0.0001)$ but no effect of block and no group-by-block interaction $(F<1.0 ; p>0.20)$.

There were very few WM-I errors made by either group of mice during these two blocks of testing (data not shown). Only two wild-type mice made WM-I errors, both during the second testing block, and only five GluRA ${ }^{-1-}$ mice made WM-I errors, all during the first block. The total number of WM-I errors made during these eight trials was summed and compared using a nonparametric Mann-Whitney rank sum test that revealed no group difference $(T=131.5 ; p>0.10)$.

\section{Experiment 3}

Acquisition of the RM component of the three-from-six radialmaze task was dependent on the hippocampus. Mice with hippocampal lesions were dramatically impaired in terms of RM errors made during acquisition (Fig. 4). These mice showed little if any improvement across the six blocks of testing. An ANOVA of RM errors revealed a significant main effect of group $\left(F_{(1,19)}=\right.$ 477.3; $p<0.0001)$, main effect of block $\left(F_{(5,95)}=47.1 ; p<\right.$ $0.0001)$, and group-by-block interaction $\left(F_{(5,95)}=37.8 ; p<\right.$ $0.0001)$. In view of the failure of the HPC-lesioned mice to show any improvement in terms of RM performance, no additional testing was conducted with these mice.

\section{Discussion}

The present study confirmed our previous observations that GluRA $^{-/-}$mice display normal spatial RM acquisition but have a selective spatial WM deficit (Reisel et al., 2002). GluRA ${ }^{-1-}$ mice
Reference memoryerrors

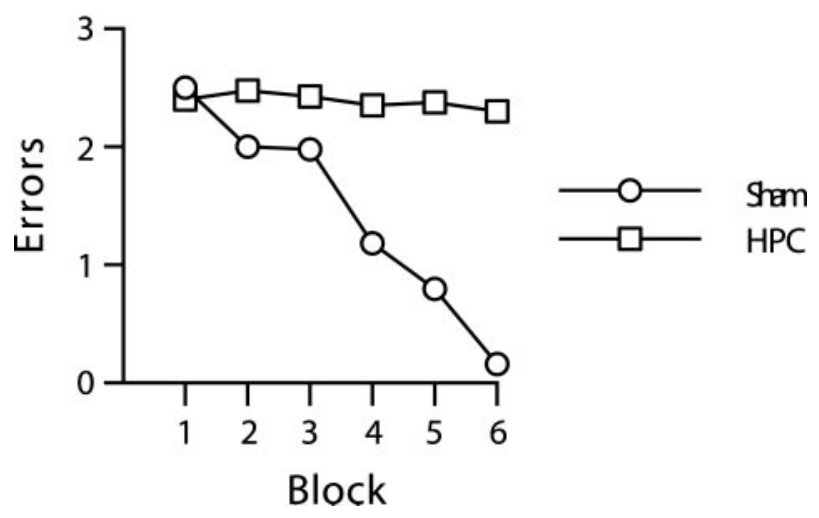

Figure 4. $\quad \mathrm{C} 57 \mathrm{BL} / 6 \mathrm{~J}$ mice with cytotoxic HPC lesions show a spatial reference memory impairment on a three-from-six radial-maze task in which doors prevent mice from making working memory errors during the acquisition phase. The mean \pm SEM number of RM errors is shown for sham (white circles) and hippocampal-lesioned (white squares) mice during six blocks of training in which doors prevented mice from making working memory errors (4 trials per block). Where error bars appear absent, the error is too small to be visible.

were able to acquire a purely RM version of the radial-maze task at the same rate as wild-type controls (experiment 2). The absence of an RM deficit in the GluRA ${ }^{-1-}$ mice was not attributable to the fact that task performance was independent of the hippocampus. Mice with hippocampal lesions were dramatically impaired on this task (experiment 3). Furthermore, when spatial WM and RM were subsequently tested simultaneously, GluRA $^{-/-}$mice were essentially unimpaired in terms of RM performance. Although there was a slight increase in the number of RM errors made by the GluRA ${ }^{-1-}$ mice on trials 1 and 2, they were unimpaired in terms of RM errors during the remaining trials and were actually performing more accurately than the controls by the end of testing. In contrast, the GluRA ${ }^{-1-}$ mice made considerably more WM errors than controls on these very same trials. This provides not only a within-subjects but also a withintrials demonstration of impaired spatial WM but spared spatial $\mathrm{RM}_{\text {in GluRA }}{ }^{-1-}$ mice. Whereas the previous dissociation between spatial WM and RM was obtained across experiments, used different sets of spatial cues, and often involved very different sensorimotor and motivational demands, in the present study both types of memory have been assessed at the same time, using identical spatial cues and with the same sensorimotor and motivational demands.

The fact that the GluRA ${ }^{-/-}$mice made significantly more RM errors than did controls during experiment 1 should not be taken as evidence against our hypothesis. As we argued previously, the increase in RM errors in the GluRA ${ }^{-1-}$ mice may have been indirectly caused by the WM deficit in these animals, producing interference that then impedes RM acquisition. The normal RM acquisition in the GluRA ${ }^{-1-}$ mice observed during experiment 2, when it was not possible to make WM errors, certainly supports such a possibility. Interestingly, when the WM component of the task was then introduced for these mice, there was no lasting RM impairment. This suggests that, once the RM component of the task has been learned, the WM deficit no longer impinges (in any lasting way) on RM performance.

The present results and previous demonstrations of intact spatial RM (Zamanillo et al., 1999; Reisel et al., 2002), in combination with the deficit in CA3 to CA1 LTP observed in hippocampal slices taken from GluRA ${ }^{-1-}$ mice (Zamanillo et al., 1999), 
provide a compelling argument that GluRA-dependent forms of synaptic plasticity at $\mathrm{CA} 3 \rightarrow \mathrm{CA} 1$ synapses are not required for hippocampus-dependent spatial RM acquisition. Importantly, lesions of the CA3 hippocampal subregion do disrupt acquisition of the standard RM water maze task (although interestingly CA3lesioned rats did develop stable place fields in their CA1 pyramidal cells and successfully acquired a hippocampus-dependent, spatial recognition water maze task) (Brun et al., 2002). Together, these results suggest that other forms of synaptic plasticity at CA3 $\rightarrow$ CA1 synapses must be capable of supporting spatial learning (Hoffman et al., 2002).

The demonstrations of impaired spatial WM in GluRA ${ }^{-/-}$ mice are consistent with previous studies that have suggested a role for LTP-like mechanisms in this particular type of hippocampal information processing. Studies using the NMDA receptor antagonist D-(-)-amino-5-phosphopentanoic acid, which blocks the induction of hippocampal LTP (Collingridge et al., 1983; Morris et al., 1986), have shown spatial WM deficits during a matching-to-position task in the water maze (Steele and Morris, 1999) and rewarded alternation on the T-maze (Tonkiss and Rawlins, 1991) and in a number of radial-maze studies (Danysz et al., 1988; Bolhuis and Reid, 1992; Caramanos and Shapiro, 1994).

Although we cannot rule out the possibility that the WM deficit may extend outside the spatial domain and may be caused by deficits in information processing in a brain area (or areas) other than the hippocampus, we feel that this is unlikely. A prime candidate for a brain structure that might contribute to such a working memory system is the prefrontal cortex (Goldman-Rakic, 1987). However, lesions of the prefrontal cortex in rodents do not, for example, produce the lasting and robust deficits during T-maze rewarded-alternation testing that we have observed with the GluRA ${ }^{-1-}$ mice. Although large medial prefrontal cortex lesions can produce mild deficits in spatial nonmatching to position (rewarded alternation) on the T-maze, performance in the lesioned animals is still well above chance levels, and any deficit is often transitory in nature (Shaw and Aggleton, 1993; Aggleton et al., 1995; Delatour and Gisquet-Verrier, 1996, 2000; Dias and Aggleton, 2000). This is in contrast to the GluRA ${ }^{-/-}$mice in which the rewarded-alternation deficit is both profound and lasting, with knock-out mice displaying chance levels of performance even after repeated test sessions (Reisel et al., 2002). In this respect, GluRA ${ }^{-/-}$mice resemble rodents with lesions to the septohippocampal system (Rawlins and Olton, 1982; Gray and McNaughton, 1983), although it should also be noted that impaired synaptic plasticity at any one of several sets of synapses within the septohippocampal system could underlie a spatial WM impairment. Tissue-specific GluRA knock-outs, in which the gene deletion can be limited to just the hippocampus or possibly even to specific subfields within the hippocampus, should resolve this issue.

The present results therefore provide compelling additional evidence of profoundly impaired spatial WM in GluRA ${ }^{-1-}$ mice that coexists with essentially unimpaired spatial RM. We have suggested previously that different mechanisms within the hippocampus may contribute differentially to hippocampal information processing (Reisel et al., 2002). We argued that a form of late-onset LTP, which is observed in GluRA ${ }^{-1-}$ mice (Hoffman et al., 2002), could be sufficient to support the gradual acquisition of, for example, a fixed, hidden-platform water maze task over several days by these mice. Similarly, such a mechanism could also underpin acquisition of the RM radial-maze task by the GluRA $^{-1-}$ mice in experiment 2 . We have also argued that, in contrast, it is difficult to see how the moment-to-moment control of behavior that is required for successful rewardedalternation performance on the elevated T-maze could be subserved by a neural mechanism that takes many minutes to change its functional properties after a new input. The ability to keep track of which arms have already been visited within a trial during the radial-maze task (i.e., the WM component) must likewise require a more flexible, rapid-onset, short-term memory system. In both of these cases, the valence of the baited arms (both arms on the T-maze and the three baited arms on the radial maze) changes within trials. To process this information efficiently, mice require a flexible, rapid-onset neuronal mechanism. We suggest that GluRA-dependent synaptic plasticity may provide such a mechanism. This proposal is consistent with the specific, rapid delivery of AMPA receptors containing GluRA subunits to synapses after LTP induction (for review, see Barry and Ziff, 2002; Malinow and Malenka, 2002).

To conclude, it seems possible that both the spatial WM and RM systems reside within the hippocampus, and that different neuronal mechanisms within the hippocampus could support these different kinds of information processing. Our results suggest that GluRA-dependent, hippocampal synaptic plasticity may provide a mechanism that subserves a rapid-onset, flexible spatial working memory system.

\section{References}

Aggleton JP, Neave N, Nagle S, Sahgal A (1995) A comparison of the effects of medial prefrontal, cingulate cortex, and cingulum bundle lesions on tests of spatial memory: evidence of a double dissociation between frontal and cingulum bundle contributions. J Neurosci 15:7270-7281.

Barry MF, Ziff EB (2002) Receptor trafficking and the plasticity of excitatory synapses. Curr Opin Neurobiol 12:279-286.

Bliss TVP, Lømo T (1973) Long-lasting potentiation of synaptic transmission in the dentate area of anaesthetized rabbit following stimulation of the perforant path. J Physiol (Lond) 232:331-356.

Bolhuis JJ, Reid IC (1992) Effects of intraventricular infusion of the $N$-methyl-D-aspartate (NMDA) receptor antagonist AP5 on spatial memory of rats in a radial maze. Behav Brain Res 47:151-157.

Brun VH, Otnæss MK, Molden S, Steffenach H-A, Witter MP, Moser M-B, Moser EI (2002) Place cells and place recognition maintained by direct entorhinal-hippocampal circuitry. Science 296:2243-2246.

Caramanos Z, Shapiro ML (1994) Spatial memory and NMDA receptor antagonists APV and MK-801: memory impairments depend on familiarity with the environment, drug dose and training duration. Behav Neurosci 108:30-43.

Collingridge GL, Kehl SJ, McLennan H (1983) Excitatory amino acids in synaptic transmission in the Schaffer collateral-commissural pathway of the rat hippocampus. J Physiol (Lond) 334:33-46.

Danysz W, Wroblewski JT, Costa E (1988) Learning impairment in rats by $N$-methyl-D-aspartate receptor antagonists. Neuropharmacology 27:653-656.

Deacon RMJ, Bannerman DM, Kirby BP, Croucher A, Rawlins JNP (2002) The effects of cytotoxic hippocampal lesions in mice on a cognitive test battery. Behav Brain Res 133:57-68.

Delatour B, Gisquet-Verrier P (1996) Prelimbic cortex specific lesions disrupt delayed-variable response tasks in the rat. Behav Neurosci 110:1282-1298.

Delatour B, Gisquet-Verrier P (2000) Functional role of rat prelimbicinfralimbic cortices in spatial memory: evidence for their involvement in attention and behavioural flexibility. Behav Brain Res 109:113-128.

Dias R, Aggleton JP (2000) Effects of selective excitotoxic prefrontal lesions on acquisition of nonmatching- and matching-to-place in the T-maze in the rat: differential involvement of the prelimbic-infralimbic and anterior cingulate cortices in providing behavioural flexibility. Eur J Neurosci 12:4457-4466.

Goldman-Rakic PS (1987) Circuitry of primate prefrontal cortex and regulation of behavior by representational memory. In: Handbook of physiology, The nervous system (Plum F, ed), pp 373-417. Bethesda, MD: American Physiological Society. 
Gray JA, McNaughton N (1983) Comparison between the behavioural effects of septal and hippocampal lesions: a review. Neurosci Biobehav Rev 7:119-188.

Hoffman D, Sprengel R, Sakmann B (2002) Molecular dissection of associative plasticity in CA1 hippocampal pyramidal neurons. Proc Natl Acad Sci USA 99:7740-7745.

Honig WK (1978) Studies of working memory in the pigeon. In: Cognitive processes in animal behavior (Hulse SH, Fowler HF, Honig WK, eds), pp 211-248. Hillsdale, NJ: Erlbaum Associates.

Jarrard LE (1983) Selective hippocampal lesions and behavior: effects of kainic acid lesions on performance of place and cue tasks. Behav Neurosci 97:873-889.

Jarrard LE (1993) On the role of the hippocampus in learning and memory in the rat. Behav Neural Biol 60:9-26.

Malinow R, Malenka RC (2002) AMPA receptor trafficking and synaptic plasticity. Annu Rev Neurosci 25:103-126.

Martin SJ, Grimwood PD, Morris RGM (2000) Synaptic plasticity and memory: an evaluation of the hypothesis. Annu Rev Neurosci 23:649-711.

Morris RGM, Anderson E, Lynch GS, Baudry M (1986) Selective impairment of learning and blockade of long-term potentiation by an $N$-methylD-aspartate receptor antagonist, AP5. Nature 319:774-776.
Olton DS, Samuelson RJ (1976) Remembrance of places passed: spatial memory in rats. J Exp Psychol Anim Behav Process 2:97-116.

Olton DS, Becker JT, Handelmann E (1979) Hippocampus, space and memory. Behav Brain Sci 2:313-366.

Rawlins JNP, Olton DS (1982) The septohippocampal system and cognitive mapping. Behav Brain Res 5:331-358.

Reisel D, Bannerman DM, Schmitt WB, Deacon RMJ, Flint J, Borchardt T, Seeburg PH, Rawlins JNP (2002) Spatial memory dissociations in mice lacking GluR1. Nat Neurosci 5:868-873.

Shaw C, Aggleton JP (1993) The effects of fornix and medial prefrontal lesions on delayed non-matching-to-sample by rats. Behav Brain Res 54:91-102.

Steele RJ, Morris RGM (1999) Delay-dependent impairment of a matchingto-place task with chronic and intrahippocampal infusion of the NMDA antagonist D-AP5. Hippocampus 9:118-136.

Tonkiss J, Rawlins JNP (1991) The competitive NMDA antagonist, AP5, but not the non-competitive antagonist, MK-801, induces a delay-related impairment in spatial working memory in rats. Exp Brain Res 85:349-358.

Zamanillo D, Sprengel R, Hvalby O, Jensen V, Burnashev N, Rozov A, Kaiser KM, Koster HJ, Borchardt T, Worley P, Lubke J, Frotscher M, Kelly PH, Sommer B, Andersen P, Seeburg PH, Sakmann B (1999) Importance of AMPA receptors for hippocampal synaptic plasticity but not for spatial learning. Science 284:1805-1811. 